Cahiers $d u$ MONDE RUSSE

\section{Cahiers du monde russe}

Russie - Empire russe - Union soviétique et États indépendants

$60 / 4 \mid 2019$

Varia

\title{
Marie MOUTIER-BITAN, Les champs de la Shoah. L'extermination des Juifs en Union Soviétique occupée, 1941-1944
}

\section{Boris Czerny}

\section{(2) OpenEdition}

1 Journals

\section{Édition électronique}

URL : https://journals.openedition.org/monderusse/11522

DOI : 10.4000/monderusse. 11522

ISSN : 1777-5388

Éditeur

Éditions de l'EHESS

\section{Édition imprimée}

Date de publication : 1 octobre 2019

Pagination : 853-855

ISBN : 978-2-7132-2797-4

ISSN : $1252-6576$

\section{Référence électronique}

Boris Czerny, "Marie MOUTIER-BITAN, Les champs de la Shoah. L'extermination des Juifs en Union Soviétique occupée, 1941-1944 », Cahiers du monde russe [En ligne], 60/4 | 2019, mis en ligne le 01 octobre 2019, consulté le 10 janvier 2023. URL : http://journals.openedition.org/monderusse/11522 ; DOI : https://doi.org/10.4000/monderusse. 11522 


\section{Marie MOUTIER-BITAN}

\section{Les champs de la Shoah}

\section{L'extermination des Juifs en Union Soviétique occupée, 1941-1944}

Paris : Éditions Passés/Composés, 477 p., index des lieux

Comme le précise le père Patrick Desbois dans la préface, l'ouvrage de Marie Moutier-Bitan ${ }^{1}$ est destiné à « permettre au lecteur de comprendre, de l'intérieur, les crimes commis contre les Juifs sur les terres de l'Union soviétique occupée par les unités allemandes en privilégiant le local, c'est-à-dire les champs, les villages, les rues dans lesquels ces crimes furent perpétrés. » (p. 11) Ce parti pris d'une description à échelle humaine, au ras des fosses où furent massacrées près de deux millions de victimes juives et plusieurs milliers de victimes non-juives, des Tsiganes et des malades mentaux que n'oublie pas de mentionner l'auteure, est illustré par les précisions apportées dans l'indication des emplacements des lieux de massacre - que des cartes permettent fort opportunément de situer sur le territoire de l'URSS -, mais également par le choix affirmé de préciser les dimensions exactes des fosses et ravins creusés par les victimes avant leur exécution et leur nombre, afin de redonner à chacune d'entre elles l'unicité d'un destin nié par les nazis. Le titre pluriel, «Les champs de la Shoah » trouve sa légitimité et son explication dans la pluralité des situations analysées par l'auteure qui souligne que « chaque lieu répondait à des problèmes topographiques, mais aussi au nombre de victimes et aux réalités locales. » (p. 308). À ce titre, il nous semble que l'établissement de typologies des pratiques d'extermination, pratiques dépendant de l'avancée de l'armée allemande sur le territoire soviétique, mais aussi du moment de leur réalisation, et la mise en exergue de la multiplicité des utilisations des camions à gaz (p. 313-317), des stratégies adoptées par certains Juifs pour survivre (p. 369-379), ainsi que l'analyse des différentes catégories de témoins (p. 339-349) (témoins risquant leur vie pour sauver un enfant, témoin passif ou, au contraire, actif, prenant part aux tueries, témoins pilleurs, etc.), est un apport important à l'étude de la Shoah dans la pluralité complexe de sa réalisation. La diversité ainsi reconstituée et réactualisée place le lecteur face aux massacres qui sont « décrits » dans chacune des six parties intitulées respectivement « Préparatifs », « Funestes moissons. Juillet $1941 »$, «Par les sentiers Battus. Août-Automne 1941 », « Nature morte. Hiver 1941-1942 », « Rase Campagne. 1942 », « Silence de la terre. 1943-1944». Ces parties se décomposent en multiples sous-chapitres aux titres évocateurs comme « La synagogue de Białystok », « Le mouroir de Transnistrie » ou bien encore « Itinéraire d'un tueur » et « Les brasiers ». Chaque chapitre constituant les différentes parties (leur nombre varie de quatre à neuf, selon les chapitres) se développe selon un schéma identique associant des éléments relevant simultanément de la macro et de la micro-histoire bien souvent illustrée par des témoignages de rescapés, d'exécutants ou de témoins. Ainsi dans le chapitre 31, « Au bout du chemin », l'introduction, «L'année 1942 fut le temps de liquidation des ghettos des territoires soviétiques occupés » (p. 306), est suivie par une focalisation sur le site de Bronnaja gora, « cette clairière dans la 
forêt [entre Pinsk et Brest] entourée de barbelés fut le lieu d'exécution d'environ 50000 personnes, en grande majorité des Juifs » (p. 306), focalisation complétée par le témoignage d'un certain Friedrich K. dont le regard, pour reprendre une terminologie formaliste " défamiliarise » le réel et l'actualise. Ce faisant, tout en ayant son autonomie et sa propre cohérence, chaque chapitre prend son sens dans le tableau général qu'il compose avec les autres, tableau d'une descente vers un néant symbolisé par le mécanisme des moulins à café industriels commandés à une grande maison de torréfaction allemande pour concasser les corps déterrés des fosses communes afin de ne pas laisser de traces des forfaits commis lors du retrait des troupes allemandes (p. 391).

Le livre Les champs de la Shoah est un livre utile, nécessaire, tout simplement parce qu'il rappelle la nécessité d'investiguer chaque meurtre, chaque massacre en détaillant la topographie, les acteurs des massacres, les victimes, le mode opératoire, etc. Mais c'est aussi un livre qui soulève un certain nombre de questions et de réflexions. Ainsi on ne peut s'empêcher de s'interroger sur la labilité d'une construction historique élaborée à partir de témoignages enregistrés à des époques distinctes (1942 pour les plus anciens et 2013 pour les plus récents) dans des contextes totalement différents (territoires nouvellement libérés ou Tel-Aviv). Le débat sur les témoignages n'est pas nouveau, mais on aurait souhaité que l'auteure justifie sa position à ce sujet. La nature des sources utilisées pose, selon nous, également problème. Certes, le sujet a été l'objet de très nombreuses études et il est matériellement impossible de toutes les citer. Cependant, on peut noter un déséquilibre bibliographique certain au détriment des livres et articles publiés récemment en Russie par la fondation Holokost, en Ukraine notamment autour de Babij Jar et en Biélorussie sur, précisément, les lieux cités par l'auteure ${ }^{2}$. Si ces absences peuvent certainement s'expliquer par des raisons linguistiques, d'autres, de sources en français, sont plus troublantes. C'est le cas par exemple de « l'oubli » concernant le livre de mémoires d'Arnold Daghani ${ }^{3}$ qui fut déporté en Transnistrie au camp de Mihaïlovka (p. 364-365) où furent assassinés des milliers de Juifs originaires de Bucovine et de Bessarabie. Enfin, il ne s'agit pas d'une critique, mais plutôt de l'ouverture d'un éventuel débat, on peut s'interroger sur la récurrence de certaines images ou motifs, comme celui de l'habit d'un parent reconnu par un rescapé dans un tas de fripes, ou d'une famille cachée trahie par les cris d'un enfant. De même, on peut se demander ce qu'apportent à la compréhension de la Shoah une certaine fictionnalisation de l'histoire et la mention de détails comme celui sur le bourreau de Stanislavov qui « revenait chez lui son manteau de cuir ruisselant des restes de ses victimes [et] qui proposait alors à son épouse de cuisiner des œufs brouillés avec de la cervelle. » (p. 343).

Toutefois, nous tenons à nouveau à le souligner, ces remarques ne retirent rien à la valeur d'un ouvrage qui, par sa diversité de tons et d'angles de visions, apporte un nouveau regard sur la Shoah en URSS.

1 - Marie Moutier-Bitan est l'auteure d'un autre livre intitulé Lettres de la Wermacht, P. : Perrin, 2014. 
2 - E. Rozenblat, I. Elenskaja, Pinskie evrei, 1939-1941 [Les Juifs de Pinsk, 1939-1941], Brest : Brest. Gos. Un-t, 1997 ; R. Černoglazoj, red., Tragedija evreev Belorussii v gody nemeckoj okupacii, 1941-1944 gg, Sbornik dokumentov i materialov [La tragédie des Juifs de Biélorussie pendant l'occupation allemande, 1941-1944. Recueil de documents], Minsk, 1997 ; L. Smilovitskij, « Evrejskie semejnye lagerja i otrjady v Belorussii, 1941-1944 gg [Camps et détachements de familles juives en Biélorussie, 1941-1944] », in Evrei Belorussii, Istorija i kul'tura, Sbornik statej [Juifs de Biélorussie, histoire et culture. Recueil d'articles], Vyp. 2, Minsk, 1998, p. 126-138; Shalom Cholawski, The Jews of Belorussia During World War II, Amsterdam : Harwood Academic Publishers, 1998 , etc.

3 - Arnold Daghani et al (trad. du roumain), La tombe est dans la cerisaie : Journal du camp de Mikhaïlovka (1942-1943), P. : Éditions Fario (« Théodore Balmoral »), 2018.

Boris Czerny

Université de Caen 